\title{
Central retinal vein occlusion and pseudoexfoliation syndrome
}

This article was published in the following Dove Press journal:

Clinical Interventions in Aging

20 May 2015

Number of times this article has been viewed

Purpose: The purpose of this study was to investigate the existence of pseudoexfoliation syndrome (PXF) as a risk factor for the development of central retinal vein occlusion (CRVO).

Methods: This was a retrospective, comparative study of the prevalence of pseudoexfoliation in three groups of patients: 48 patients with CRVO, 164 patients with branch retinal vein occlusion (BRVO), and 70 control patients (70 eyes). All patients were phakic and had no previous diagnosis of glaucoma. Patients were matched in terms of age and systemic hypertension. All patients had normal intraocular pressure (IOP) at presentation (defined as less than or equal to $21 \mathrm{mmHg}$ ).

Results: In the CRVO group, 14 out of 48 patients were diagnosed as having PXF (29.17\%). In the BRVO group, 14 out of 164 patients had PXF (8.5\%), and in the control group, six out of 70 patients had PXF (8.6\%). Differences of percentage between groups were statistically significant $\left(P<0.001, \chi^{2}\right.$ test). When comparing patient subgroup with ischemic CRVO with subgroup with non-ischemic CRVO, we found that in the ischemic CRVO group, 13 out of 27 patients were diagnosed as having PXF (48.15\%), and in the non-ischemic CRVO group, one out of 21 patients was diagnosed as having PXF (4.7\%; $P<0.001, \chi^{2}$ test). The relative odds of having CRVO in patients with PXF versus patients without PXF were 4.406 (confidence interval [CI], 2.03-9.54).

Conclusion: PXF and CRVO, especially ischemic, are strongly associated in our study. Our results indicate that PXF might be an independent factor for CRVO, as it is related with CRVO independently from glaucoma.

Keywords: pseudoexfoliation, ischemic and non-ischemic central retinal vein occlusion, branch retinal vein occlusion, glaucoma

\section{Introduction}

Pseudoexfoliation syndrome (PXF) is an age-related disease characterized by the production and accumulation of a fibrillar extracellular material in several ocular tissues. It is considered to be the overall most common identifiable cause of glaucoma, and in some countries it accounts for the majority of the glaucoma cases. Similar material has also been detected in skin and connective tissue of various visceral organs. ${ }^{1,2}$

In the eye, PXF is characterized clinically by small, white deposits of material in the anterior segment, most commonly on the pupillary border and anterior lens capsule. The diagnosis can be set only after a careful slit-lamp examination under pupillary dilation in most of the cases; thus, it frequently goes undiagnosed. Cataract surgery bears risk for complications in such eyes due to poor pupillary dilation and inadequate zonular support; thus, preoperative diagnosis of PXF is essential. ${ }^{1}$

Retinal vein occlusions (RVO) are the second most common blinding vascular retinal disorder after diabetic retinopathy. There are two main types of RVO: branch RVO (BRVO), when the occlusion involves one temporal or nasal branch of the

Correspondence: Georgios A Kontadakis Ophthalmiatrio Eye Hospital of Athens, Eleftheriou Venizelou 26, GR 106 72, Athens, Greece

Email kontadas@yahoo.com 
central retinal vein exclusively; and central RVO (CRVO), when the occlusion involves the central retinal vein. The most common vision-threatening complications are retinal ischemia and macular edema. The pathogenesis of RVO is yet not well understood. The main known risk factors of CRVO are hypertension, diabetes mellitus, and open-angle glaucoma (OAG). ${ }^{3-5}$ The purpose of our study was therefore to investigate the existence of PXF as a risk factor for the development of CRVO.

\section{Methods}

This was a retrospective case-control study of patients with CRVO and controls presenting for examination in the Ophthalmiatreio Eye Hospital of Athens and the Ophthalmology Department of the University Hospital of Heraklion, Heraklion, Greece. Patients were allocated in three groups, one group with diagnosis of CRVO, one group with BRVO, and a group of controls, with patients presenting for regular examination. Patients in the control group were matched with CRVO patients in terms of age and systemic cardiovascular disease. All patients were phakic, and had no diagnosis of glaucoma in their ophthalmic history. Patients that presented from June 2010 until June 2014 and met the inclusion criteria were enrolled.

Inclusion criteria in the CRVO group were: 1) diagnosis of CRVO confirmed by clinical examination and fluorescein angiography, and 2) normal intraocular pressure (IOP) at presentation (defined as less than or equal to $21 \mathrm{mmHg}$, normal appearance of optic nerve head on fundoscopy, and normal gonioscopy). CRVO cases were diagnosed clinically based on the acute onset of visual acuity loss associated with the following findings at ophthalmoscopy: scattered superficial and intraretinal hemorrhages, macular edema, vascular tortuosity, and optic disc edema. Patients were classified into non-ischemic and ischemic CRVO categories based on fundoscopic and fluorescein angiography findings. However, best corrected visual acuity (BCVA) was also used as a criterion for the classification of CRVO as ischemic or non ischemic. In the BRVO group, inclusion criteria were: 1) diagnosis of BRVO confirmed by clinical examination and fluorescein angiography, 2) normal IOP at presentation, 3) normal appearance of optic nerve head on fundoscopy, and 4) normal gonioscopy. For the control group, we recruited patients presenting in the outpatients department for ophthalmic examination with normal IOP and without any retinal vascular abnormalities. Patients with previous diagnosis of glaucoma or ocular hypertension in their ophthalmic history and patients operated for cataract were excluded from the study.
All patients included in the study underwent slit-lamp examination under pupillary dilation in order to define the existence of PXF. The diagnosis of PXF was made by visualization of exfoliation material on the papillary margin and/ or on the anterior lens surface after pupillary dilation.

We also assessed medical history of all patients, including systemic hypertension, diabetes, cardiovascular disease, thyroid disease, stroke, peripheral vascular disease, and use of medications. Patients reporting poorly controlled systemic disease were excluded from the study.

\section{Statistical analysis}

The percentage of patients with PXF in the group of patients with CRVO was compared with the percentage with PXF in the BRVO group and in the control group. The CRVO group was divided in two subgroups, including patients with ischemic CRVO and patients with non-ischemic CRVO, and percentage of PXF was also compared between these subgroups. The odds ratio of CRVO in patients with PXF versus controls was also calculated.

\section{Ethical approval}

The study was approved by the Institutional Review Boards of Ophthalmiatreio Eye Hospital of Athens and the University Hospital of Heraklion.

\section{Results}

Forty-eight patients with CRVO, 164 patients with BRVO, and 70 control patients were included in the study. Mean age of the patients in the CRVO group was 67 years (standard deviation [SD], 14.26; range, 33-90 years), in the BRVO group it was 70 years (SD, 9.15; range, 39-93 years), and in the control group it was 67 years (SD, 10.64; range, 4089 years). Differences were not statistically significant between groups $(P=0.105$, one-way analysis of variance [ANOVA]). The percentage of the other main risk factors for CRVO (systemic hypertension, hyperlipidemia, and diabetes mellitus) did not differ between groups (Table 1).

In the CRVO group, 14 out of 48 patients were diagnosed as having PXF (29.17\%). In the BRVO group, 14 out of 164 patients had PXF (8.54\%), and in the control group, six out of 70 patients had PXF (8.57\%). Differences of percentage between groups were statistically significant $(P<0.001$, $\chi^{2}$ test) (Figure 1$)$.

In the comparison of subgroups with ischemic and nonischemic CRVO, we found statistically significant differences in the percentage of PXF between them. In the ischemic CRVO group, 13 out of 27 patients were diagnosed as having 
Table I Patient demographics and comparisons between groups

\begin{tabular}{|c|c|c|c|c|}
\hline & CRVO & BRVO & Control group & $P$-value \\
\hline$n(\%)$ & 48 & 164 & 70 & \\
\hline Age, years (mean[SD]) & $\begin{array}{l}67 \text { (SD 14.26, } \\
\text { range 33-90) }\end{array}$ & $\begin{array}{l}70 \text { (SD 9.15, } \\
\text { range 39-93) }\end{array}$ & $\begin{array}{l}67 \text { (SD 10.64, } \\
\text { range 40-89) }\end{array}$ & 0.105 (ANOVA) \\
\hline Systemic hypertension & $25(52 \%)$ & $94(57 \%)$ & $42(60 \%)$ & 0.69 (chi-square test) \\
\hline Hyperlipidemia & I3 (27\%) & $38(23 \%)$ & 17 (24\%) & 0.85 (chi-square test) \\
\hline Diabetes mellitus & $5(10 \%)$ & $33(20 \%)$ & $15(21 \%)$ & 0.25 (chi-square test) \\
\hline PXF & $14(29 \%)$ & I4 (8.5\%) & $6(8.6 \%)$ & $<0.00$ I (chi-square test) \\
\hline
\end{tabular}

Note: Statistically significant $P$-values are in bold font.

Abbreviations: $n$, number of patients; CRVO, central retinal vein occlusion; BRVO, branch retinal vein occlusion; SD, standard deviation; ANOVA, analysis of variance; PXF, pseudoexfoliation syndrome.

PXF (48.15\%), and in the non-ischemic CRVO group, one out of 21 patients was diagnosed as having PXF (4.76\%; $P<0.001, \chi^{2}$ test) (Table 2 and Figure 2).

By calculation of odds ratios in the group of patients with CRVO versus the patients without CRVO, we found that the relative odds of having CRVO in patients with PXF in comparison to patients without PXF were 4.406 (confidence interval [CI], 2.03-9.54). Consequently, PXF is strongly associated with increased risk of having CRVO.

\section{Discussion}

The results of our study suggest that PXF might be a significant risk factor for the development of CRVO. The pathogenesis of CRVO is not completely understood yet. It is thought to be a compartment syndrome, since in a $1.5 \mathrm{~mm}$ diameter area, the central retinal artery, the central retinal vein, and the optic nerve coexist. The combination of hemodynamic changes (venous stasis), degenerative changes of the vessel wall, and blood hypercoagulability is involved in retinal thrombogenesis. Thrombotic occlusion is thought to develop as the result of an increase in the arterial diameter; changes in the scleral ring, in combination with possible

\section{PXF percentage}

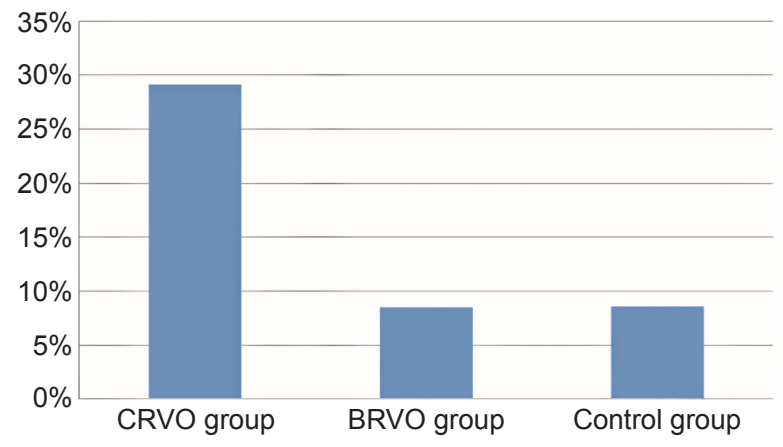

Figure I Histogram representing the percentage of PXF among each of the groups in the study.

Abbreviations: PXF, pseudoexfoliation syndrome; CRVO, central retinal vein occlusion; BRVO, branch retinal vein occlusion. systemic factors, together cause a decrease in the venous lumen, increased turbulence, damage to the endothelium, and thrombus formation. ${ }^{3-7}$

It has already been identified that significant risk factors for the development of CRVO are 1) systemic hypertension, 2) diabetes mellitus, 3) hyperlipidemia, and 4) glaucoma. ${ }^{8-11}$ The first three factors are related to CRVO due to the vascular abnormalities they bear, and the latter is related to CRVO due to high IOP that may lead to vessel thrombosis. In CRVO, elevated IOP has been theorized to deform the lamina cribrosa. If the vessels become strained by this deformation, the central retinal vein is probably more affected than the less pliable central retinal artery. Turbulent blood flow within the pinched central retinal vein may damage the inner lining of the vessel wall and result in the formation of a blood clot. In addition, elevated IOP may oppose and reduce blood flow through the retinal vessels, potentially causing blood to stagnate and thereby contribute to thrombus formation. ${ }^{12}$

Pseudoexfoliation is the most common identifiable cause of OAG, affecting a mostly aging population. ${ }^{1,13,14}$ In the Blue Mountain study, patients with PXF in either eye have a two- to threefold higher risk of OAG, while eyes with PXF had fivefold increased risk for OAG, even though OAG was often associated with only modest increase in IOP. Retinal and optic nerve head pathology of pseudoexfoliation glaucoma is considered to be similar if not identical to that of primary OAG. ${ }^{13}$

Table 2 Comparison between ischemic and non-ischemic CRVO

\begin{tabular}{llll}
\hline & $\begin{array}{l}\text { Ischemic } \\
\text { CRVO }\end{array}$ & $\begin{array}{l}\text { Non-ischemic } \\
\text { CRVO }\end{array}$ & P-value \\
\hline $\mathrm{n}$ & 27 & 21 & \\
$\begin{array}{l}\text { Age, years } \\
\text { (mean[SD]) }\end{array}$ & 69 (SD I3.I2) & 63 (SD I5.3I) & 0.174 (t-test) \\
PXF & 13 & 1 & \\
PXF\% & $48 \%$ & $4.76 \%$ & 0.00 I (chi-square test) \\
\hline
\end{tabular}

Abbreviations: $n$, number of patients; PXF, pseudoexfoliation syndrome; CRVO, central retinal vein occlusion; SD, standard deviation. 


\section{PXF percentage}

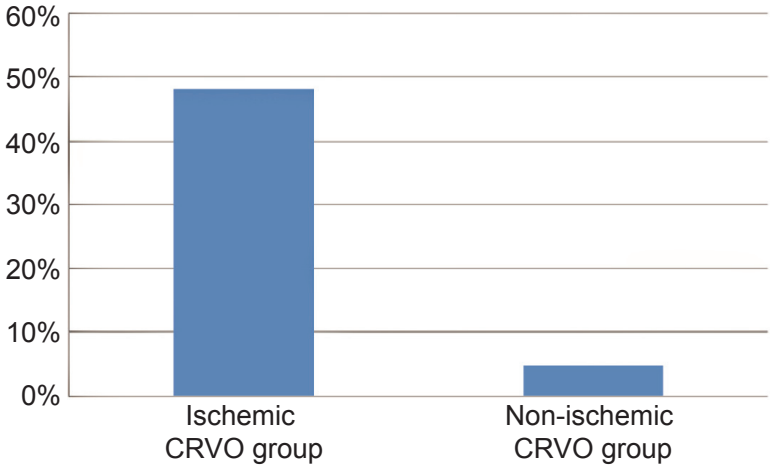

Figure 2 Histogram representing the percentage of PXF in the two subgroups of ischemic central retinal vein occlusion (CRVO) and non-ischemic CRVO. Abbreviation: PXF, pseudoexfoliation syndrome.

In our study, we did not include patients with glaucoma in order to identify PXF as an independent risk factor from glaucoma in the development of CRVO. It is not needed to develop PXF glaucoma in order for PXF to be a risk factor for CRVO, according to our results. In a study of ocular hemodynamics in patients with PXF and pseudoexfoliative glaucoma, it was found that blood flow in retinal and bulbar vessels is compromised even in PXF patients without glaucoma in comparison to controls. ${ }^{15}$ This decrease in retrobulbar circulation may participate in the multifactorial pathogenetic mechanism of CRVO. In addition, in other studies, it has been demonstrated that eyes with PXF without clinically evident glaucoma may have detectable structural damage in the optic nerve. ${ }^{16,17}$ Therefore, it is possible that glaucomarelated complications of $\mathrm{PXF}$, such as increased risk for CRVO, exist prior to clinical manifestation of glaucoma in these patients. We postulate that in PXF patients, spikes of IOP may come along before glaucoma manifestation and excite CRVO formation.

Previous studies have also found that PXF may be a risk factor for CRVO. ${ }^{18-20}$ Ritch et $\mathrm{al}^{19}$ and Cursiefen et $\mathrm{al}^{18}$ both used histology and have shown that there is correlation of CRVO with PXF in their studies. Especially the latter study refers to ischemic CRVO. In our present study, we also found that the percentage of patients with PXF in the ischemic group is significantly higher in comparison to the non-ischemic group. In contrast to previous studies, in our current study we enrolled only patients without glaucoma in order to examine the association of PXF with CRVO independently of glaucoma.

In conclusion, our results indicate that PXF might be an independent risk factor for CRVO, as it is correlated with CRVO independently from glaucoma. Further investigation is needed to explain the mechanism responsible for this clinical observation.

\section{Disclosure}

The authors report no conflicts of interest in this work.

\section{References}

1. Ritch R, Schlötzer-Schrehardt U. Exfoliation syndrome. Surv Ophthalmol. 2001;45:265-315.

2. Schlötzer-Schrehardt UM, Koca MR, Naumann GOH, Volkholz H. Pseudoexfoliation syndrome. Ocular manifestation of a systemic disorder? Arch Ophthalmol. 1992;110:1752-1756.

3. Mcallister IL. Central retinal vein occlusion: a review. Clin Experiment Ophthalmol. 2012;40:48-58.

4. Wong TY, Scott IU. Clinical practice. Retinal-vein occlusion. $N$ Engl J Med. 2010;363:2135-2144.

5. Koizumi H, Ferrara DC, Bruè C, Spaide RF. Central retinal vein occlusion case-control study. Am J Ophthalmol. 2007;144:858-863.

6. Hayreh SS. So called "central retinal vein occlusion". I. Pathogenesis, terminology, clinical features. Ophthalmologica. 1976;172:1-13.

7. Rehak M, Wiedemann P. Retinal vein thrombosis: Pathogenesis and management. Journal of Thrombosis and Haemostasis. 2010; 8:1886-1894.

8. David R, Zangwill L, Bardarna M, Yassur Y. Epidemiology of retinal vein occlusion and its association with glaucoma and increased intraocular pressure. Ophthalmologica. 1988;197:69-74.

9. Jonas JB, Nangia V, Khare A, Sinha A, Lambat S. Prevalence and associations of retinal vein occlusions: the Central India Eye and Medical Study. Retina. 2013;33:152-159.

10. Stem MS, Talwar N, Comer GM, Stein JD. A longitudinal analysis of risk factors associated with central retinal vein occlusion. Ophthalmology. 2013;120:362-370.

11. Zhou JQ, Xu L, Wang S, et al. The 10-year incidence and risk factors of retinal vein occlusion: the Beijing eye study. Ophthalmology. 2013; 120:803-808.

12. Hayreh SS, Zimmerman MB, Beri M, Podhajsky P. Intraocular pressure abnormalities associated with central and hemicentral retinal vein occlusion. Ophthalmology. 2004;111:133-141.

13. Mitchell P, Wang JJ, Hourihan F. The relationship between glaucoma and pseudoexfoliation: The Blue Mountains Eye Study. Arch Ophthalmol. 1999;117:1319-1324.

14. You QS, Xu L, Wang YX, et al. Pseudoexfoliation: normative data and associations: The Beijing eye study 2011. Ophthalmology. 2013;120:1551-1558.

15. Yüksel N, Karabaş VL, Arslan A, Demirci A, Cağlar Y. Ocular hemodynamics in pseudoexfoliation syndrome and pseudoexfoliation glaucoma. Ophthalmology. 2001;108:1043-1049.

16. Yüksel N, Altintaş O, Çelik M, Ozkan B, Çağlar Y. Analysis of retinal nerve fiber layer thickness in patients with pseudoexfoliation syndrome using optical coherence tomography. Ophthalmologica. 2007;221:299-304.

17. Mohamed MM. Detection of early glaucomatous damage in pseudo exfoliation syndrome by assessment of retinal nerve fiber layer thickness. Middle East Afr J Ophthalmol. 2009;16:141-145.

18. Cursiefen C, Hammer T, Küchle M, Naumann GOH, SchlötzerSchrehardt US. Pseudoexfoliation syndrome in eyes with ischemic central retinal vein occlusion. A histopathologic and electron microscopic study. Acta Ophthalmol Scand. 2001;79:476-478.

19. Ritch R, Prata TS, De Moraes CG, et al. Association of exfoliation syndrome and central retinal vein occlusion: an ultrastructural analysis. Acta Ophthalmol. 2010;88:91-95.

20. Saatci OA, Ferliel ST, Ferliel M, Kaynak S, Ergin MH. Pseudoexfoliation and glaucoma in eyes with retinal vein occlusion. Int Ophthalmol. 1999;23:75-78 


\section{Publish your work in this journal}

Clinical Interventions in Aging is an international, peer-reviewed journal focusing on evidence-based reports on the value or lack thereof of treatments intended to prevent or delay the onset of maladaptive correlates of aging in human beings. This journal is indexed on PubMed Central, MedLine,

\section{Dovepress}

CAS, Scopus and the Elsevier Bibliographic databases. The manuscript management system is completely online and includes a very quick and fair peer-review system, which is all easy to use. Visit http://www.dovepress. $\mathrm{com} /$ testimonials.php to read real quotes from published authors. 